\section{Revolution in physics}

The History of Quantum Theory. By Friedrich Hund. Translated by Gordon Reece. Pp. 260. (Harrap: London, March 1974.) £6.10.

THE main part of this book is a blowby-blow account of the development of quantum theory in about the first 28 years of the present century, from Planck's introduction of light quanta through the 'old quantum theory' up to the formulation of quantum mechanics and wave mechanics culminating in Dirac's relativistic equation for the electron. The whole of existing basic quantum theory may be said to have been produced in about the three years 19258. The school of Max Born in Göttingen, including Heisenberg, Jordan and Pauli played a leading part at that time and Professor Hund was himself a prominent member. So here we have a first-hand account of all that was achieved in those heroic times of phenomenal activity, as well as the story of what had led up to this. It would be almost impossible for anyone ever again to provide such a survey, and the history of science will owe a great deal to Professor Hund for giving it.

The important thing is that this account has been written. It would, however, have been interesting to know more about the history of the history. The brief foreword is undated and there are no bibliographical particulars whatever of the original German publication save for its title: Geschichte der Quantentheorie. There are a few references to relevant items in the literature after about 1930 up to the present, but the text could have been written any time in that interval.

Within its set design, the history is comprehensive and exceedingly well digested. It is clear and it is also very terse. Its value as a historical document is all the greater for these reasons. But they almost inevitably eliminate the excitement and romance. Before the first World War there were tremendously revolutionary ideas about atoms, photons, space and time. After that there was an interlude when all kinds of things about atomic spectra-transition rules, line intensities and the like-were got with extreme ingenuity by using a wierd combination of classical and quantum physics with astonishing elaboration and success but with no new basic idea. Then suddenly quantum mechanics in its several varieties came into bloom and fruition; its doing so seemed curiously inevitable though the forms were wholly unexpected. The facts are all here on permanent record; however, there has never been a time like that in the history of physical thought and one doubts whether the reader in a different epoch will be able

to re-create from the bare facts the stimulus of living through it.

Also I am convinced that no historian has yet explained how there came to be such a rush of discovery by so many scientists in so many places all at the same time. All previous fundamental advances seem to have been largely the work of one outstanding individual at a time-one may think of Newton, Maxwell, Rutherford, Einstein, Bohr as examples-but in 1925-8 fundamental contributions came from maybe 20 individuals of comparable stature (no doubt some more comparable than others), several of them only half the age of the others, working in some 10 or so different institutions. Hund does

\title{
Some useful ammunition for worried ornithologists
}

The Seabirds of Britain and Ireland. By Stanley Cramp, W. R. P. Bourne and David Saunders. Pp. 287. (Collins: London, 1974.) £3.50.

Here is a classic for the last-page-first reader since the final appendix clearly illustrates both the origins and the uses of this book. In this appendix figures are given which demonstrate the fate of puffins at various breeding colonies in Britain and Ireland during the last 100 years or so. The immense colonies on so many of Britain's islands at the turn of the century are all seriously depleted or even deserted; the 20,000 birds on Puffin Island, County Kerry in 1965 had declined to 3,700 five years later. Not that all is gloom with Britain's seabirds. As this book shows, gannet, kittiwakes and fulmars have all had population expansions, even explosions, in recent decades. Not only are the causes of these fluctuations unclear but all too often their extent is little more than guesswork. In order to build a sound basis for assessing future fluctuations, the Seabird Group, founded in 1965 , took upon itself the onerous task of making as full as possible a census of the breeding seabirds of Great Britain and Ireland. After a pilot study in the year of the Torrey Canyon disaster, the full survey was carried out in 1969-70. "Operation Seafarer" as it was known, yielded several volumes of detailed results. The essence of these forms the basis of this book.

Twenty-four regularly breeding species are considered under the title of seabirds although such thoroughly maritime birds as the eider duck and the oyster catcher are arbitrarily excluded. The bulk of the text is composed of a section devoted to each species and covering their identification, breeding, world distribution and past and present status in the areas surveyed, together with a note on the indeed indicate these aspects in a brief note on "Centres of Research" at the end of his book; it contains a most interesting diagram on page 251 showing the times when a number of the leading workers made their contributions, but this is presented without explanation or comment. Possibly someone else, working from all this material so ably marshalled by Professor Hund, will some day succeed in revealing the underlying historical causes of the phenomenon.

The book is expensive for its number of pages, but perhaps not for the concentration of information they convey. Gordon Reece's translation is outstanding.

W. H. MCreA

census method used for each species except, inexplicably, any of the gulls. These sections are sound and well referenced. Only the identification details, even in conjunction with the rather mean drawings and photographs, leave something to be desired; but they are probably superfluous anyway.

The rest of the book consists of three chapters on seabirds--dealing with their biology, the threats to their existence and their present numbers and changing fortunes. These make informative, if not always elegant, reading. At the back of the book are placed a series of maps and tables. The former, one per species, show the locality, number and size of the breeding colonies discovered in Operation Seafarer. Crispin Fisher is to be congratulated on presenting in them a large deal of information in a masterly way. The tables are an inconsistent set, sometimes supplementing the data in the maps, sometimes duplicating it.

Much of the information in the book is unique, all will be valuable. It is perhaps a pity that room could not be found for a more general chapter on bird population changes covering at least Europe and including inland as well as seabirds. It would also have been fascinating to know more about the organisation and logistics of the survey. We are told something about the census methods, which ranged from the smelling out of storm petrels' nesting sites to aerial photography of gannet colonies. But exactly how the hundreds of intrepid observers worked we never find out.

Despite some deficiencies this book should appeal to all who have more than just a passing interest in birds. As the sides line up for forthcoming battles over North Sea oil landing sites and other coastal attacks, it will be a source of much useful ammunition.

Peter Newmark 